\title{
In-Use Emissions and Estimated Impacts of Traditional, Natural- and Forced-Draft Cookstoves in Rural Malawi
}

\author{
Roshan Wathore, $^{\dagger}$ Kevin Mortimer, ${ }^{\ddagger}$ and Andrew P. Grieshop*, ${ }^{*}+0$ \\ ${ }^{\dagger}$ Department of Civil, Construction and Environmental Engineering, North Carolina State University, Raleigh, North Carolina \\ 27695-7908, United States \\ ${ }^{\ddagger}$ Department of Clinical Sciences, Liverpool School of Tropical Medicine, Liverpool L3 5QA, United Kingdom
}

Supporting Information

ABSTRACT: Emissions from traditional cooking practices in low- and middle-income countries have detrimental health and climate effects; cleaner-burning cookstoves may provide "cobenefits". Here we assess this potential via in-home measurements of fuel-use and emissions and real-time optical properties of pollutants from traditional and alternative cookstoves in rural Malawi. Alternative cookstove models were distributed by existing initiatives and include a low-cost ceramic model, two forced-draft cookstoves (FDCS; Philips HD4012LS and ACE-1), and three institutional cookstoves. Among household cookstoves, emission factors (EF; g (kg wood) $)^{-1}$ ) were lowest for the Philips, with statistically significant reductions relative to baseline of $45 \%$ and $47 \%$

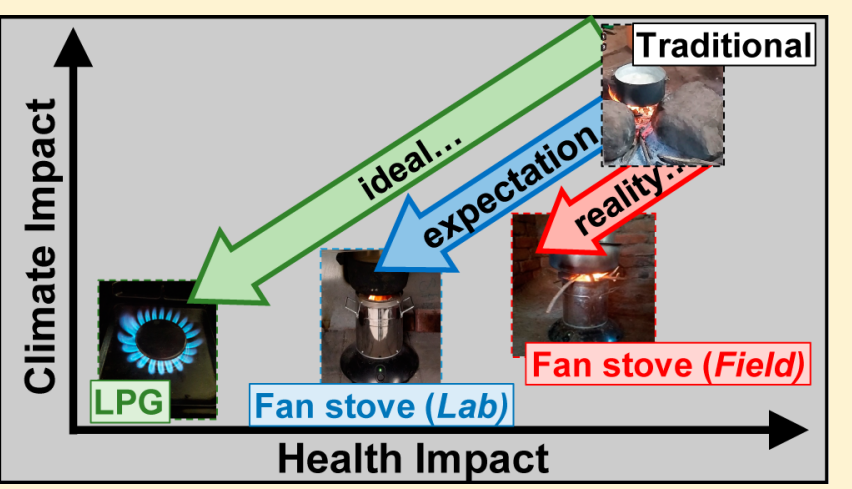
for fine particulate matter $\left(\mathrm{PM}_{2.5}\right)$ and carbon monoxide (CO), respectively. The Philips was the only cookstove tested that showed significant reductions in elemental carbon (EC) emission rate. Estimated health and climate cobenefits of alternative cookstoves were smaller than predicted from laboratory tests due to the effects of real-world conditions including fuel variability and nonideal operation. For example, estimated daily PM intake and field-measurement-based global warming commitment (GWC) for the Philips FDCS were a factor of 8.6 and 2.8 times higher, respectively, than those based on lab measurements. In-field measurements provide an assessment of alternative cookstoves under real-world conditions and as such likely provide more realistic estimates of their potential health and climate benefits than laboratory tests.

\section{INTRODUCTION}

Roughly 2.7 billion people depend on the burning of biomass and other solid fuels in three stone fires (TSF) and other traditional cookstoves for their day-to-day cooking purposes. ${ }^{1}$ Cookstoves have environmental and health impacts on an enormous scale, ${ }^{2,3}$ due in large part to emissions of products of incomplete combustion (PIC) such as $\mathrm{CO}, \mathrm{PM}_{2.5}$, methane $\left(\mathrm{CH}_{4}\right)$, and polycyclic aromatic hydrocarbons (PAHs). Black carbon (BC), commonly known as soot, is an aerosol component formed during combustion that is estimated to have the second highest global warming impact after $\mathrm{CO}_{2}{ }^{4,5}$ Approximately $25 \%$ of global annual BC emissions and $60-$ $80 \%$ of Africa's and Asia's BC emissions that are not from open burning (e.g., wildfires) are from domestic solid fuel combustion. . $^{\mathrm{BC}}$ is coemitted with organic carbon (OC), a component which is often regarded to have a cooling impact on climate, ${ }^{6}$ although recent studies suggest that the OC fraction (generally called brown carbon or $\mathrm{BrC}$ ) that absorbs radiation at short wavelengths contributes significantly to warming. ${ }^{7-9}$ The net climate impacts of cooking-related aerosol emissions are uncertain, though likely warming. ${ }^{10-13}$ Replacement of traditional cookstoves with alternative technologies thus has the potential to provide considerable climate and health benefits by reducing emissions and human exposures. ${ }^{14,15}$

Efforts to reduce these impacts have spurred the development of a range of alternative cookstoves with varying configurations, levels of sophistication, and performance. Models range from rudimentary low-cost cookstoves often built from local materials to mass produced state-of-the-art forced draft cookstoves (FDCS) which use electrically driven fans for improved combustion efficiency. Using laboratory emission factors (EF; $\left.\mathrm{g}(\mathrm{kg} \text { wood })^{-1}\right)$, Grieshop et al. ${ }^{16}$ estimated that health (quantified as daily intake of $\mathrm{PM}_{2.5}$ for users) and climate impacts (quantified as global warming commitment or GWC) of various cookstove-fuel combinations can each span 2 orders of magnitude, with all biomass-burning cookstoves having greater impacts than "modern" fuel stoves such as LPG and kerosene.

Received: November 4, 2016

Revised: January 1, 2017

Accepted: January 6, 2017

Published: January 6, 2017 
This variation across cookstoves types and the need to benchmark performance has led to the development of a tier framework, ${ }^{17}$ with emissions and other parameters quantified during standardized laboratory testing (e.g., the water boiling test; $\mathrm{WBT}^{18}$ ). While laboratory testing is required for benchmarking, field data indicate that laboratory tests typically greatly overestimate performance relative to in-home use. For example, field PM EFs are 2-5 times higher than those measured during WBT tests. ${ }^{19-21}$ This is important because benefit estimates for alternatives rely on accurate estimates of real-world performance. ${ }^{20-22}$ FDCSs have the potential to greatly reduce emissions via improved combustion efficiency; their laboratory $\mathrm{PM}_{2.5}$ and elemental carbon (EC) EFs are an order of magnitude lower than those for traditional stoves, ${ }^{23,24}$ putting FDCSs in the highest tiers (3 or 4) for indoor PM emissions. However, in-field measurements of emissions from FDCS are limited, report real-time BC concentrations (not EFs), and neglect other species (e.g., $\left.\mathrm{CO}_{2}, \mathrm{OC}\right) .^{25,26}$

Carbon finance has been held up for its potential to yield cobenefits by enabling access to improved cookstove technologies by poor households. ${ }^{27}$ While flagging carbon markets $^{28,29}$ and evidence from early efforts ${ }^{30}$ call the near-term practicality of this into question, it remains an important possible source of finance. Current carbon finance methodologies include greenhouse gases (GHGs) but fail to account for the climate impact of PICs such as BC, CO, OC, and nonmethane hydrocarbons (NMHC), mainly because of the high uncertainty and variability in their emissions ${ }^{28,31}$ and the differing spatial and temporal scales of their impacts relative to GHGs. ${ }^{32,33}$ BC dominates cookstove PIC climate impacts ${ }^{6,16}$ and has become a focus for mitigating near-term climate change. In response, the Gold Standard Foundation recently developed a simplified methodology, ${ }^{34}$ which relies on either laboratory or (preferred) field-based emission measurements, with the latter collected using the Kitchen Testing Protocol (KPT), ${ }^{35}$ to incentivize $\mathrm{BC}$ mitigation efforts. However, the Gold Standard does not require field emission measurements to be made (only measurements of fuel use reductions), ${ }^{28}$ and as noted above few cookstoves have actually been measured in the field. Therefore, an important missing piece is a rigorous understanding of in situ emissions from cookstove technologies and the extent to which the emission reductions indicated by laboratory testing are achieved under real-world conditions.

To address this gap, we conducted an evaluation of in-field emissions in Malawi, Africa focusing on two pre-existing cookstove programs. The specific objectives of this work were: 1) to measure fuel use and emission factors from in-home use of alternative and baseline household and institutional cooking technologies; 2) compare emission factors and rates with existing measurements and emission "tiers"; 3) analyze realtime optical properties (absorption and scattering) of aerosols during in-home use; and 4) estimate and compare health and climate impacts/benefits suggested by lab and field-based measurements.

\section{METHODS}

2.1. Study Site Details - Malawi. Malawi is a small, landlocked country in southeastern Africa in which over $90 \%$ of the population uses biomass as their main source of domestic energy. ${ }^{36,37}$ It is one of the most densely populated countries in Sub-Saharan Africa and among the poorest in the world, ranking 173 among 188 countries in Human Development Index. $^{38}$ High poverty rates, dependence on unsustainably harvested firewood, and a predominantly rural population means there is a great need for improvements in household energy systems and makes Malawi an ideal location to study the impacts of alternative cookstove technologies. ${ }^{39-41}$

Household emission measurements of uncontrolled in-home cookstove use (following the KPT protocol ${ }^{35}$ ) took place during routine cooking activities in September-October 2015 (the hot and dry season). Emission tests were completed in two communities on cookstoves at opposite ends of the technology spectrum discussed above. In one, the Cooking and Pneumonia Study (CAPS; www.capstudy.org), led by the Liverpool School of Tropical Medicine (LSTM), distributed limited quantities of two FDCS models (Philips HD4012LS and ACE-1; cost 90 USD) as part of pilot activities for this community-level randomized controlled trial of the effects of the Philips HD4012LS cookstove on the incidence of pneumonia in children under the age of $5 .^{42}$ FDCS use was not widespread in this community; on the order of 10-20 cookstoves had been distributed. In the other, the nongovernmental organization (NGO) Concern Universal (CU; www.concern-universal.org) helped establish nearly universal distribution of the Chitetezo Mbaula (CM) cookstove, a low-cost ( 1-2 USD), locally produced, natural-draft clay cookstove, with the main objective of reducing fuel use by users and with funding from the sale of carbon credits. ${ }^{43}$ In both communities, traditional three stone fires or simple mud stoves (here grouped together as "Traditional") were in use by some households and were also tested. Cookstoves are shown in Figure S1 in the Supporting Information (SI). In-home cookstove use included cooking of traditional foods such as Nsima (a corn-flour porridge, the staple food of Malawi) or rice, preparing vegetables or meat, and heating water for bathing and took place inside, in semicovered verandas and outside.

In addition to in-home testing, Controlled Cooking Tests $(\mathrm{CCT})^{44}$ were conducted on several larger, wood-burning institutional cookstoves being piloted at an orphanage. Institutional cookstoves are used where a large number of people are fed; they are much larger than household cookstoves to accommodate a dedicated, large cooking pot (80-100 L) that sits inside the stove body, enabling more efficient heat transfer. Institutional cookstoves tested included a large institutional three stone fire (I-TSF), Aleva (AL), Mayankho (MA), and the JumboZama (JZ). The JumboZama is a scaledup version of the Zama Zama rocket gasifier cookstove (Rocket Works, Durban, South Africa) built inside a masonry housing. Figure S2 (SI) shows the institutional cookstoves tested, and Table S1 summarizes tests conducted during the campaign.

2.2. Sampling Methodology. In-home emission measurements were performed using the portable Stove Emissions Measurement System (STEMS; Figure S3 in the SI), which utilizes the "sensor board" from a Portable Emission Measurement System (Aprovecho Research, Cottage Grove, OR). The STEMS runs on a $12 \mathrm{~V}$ battery and measures real-time $(2 \mathrm{~s})$ concentrations of carbon dioxide $\left(\mathrm{CO}_{2}\right)$, carbon monoxide (CO), temperature, relative humidity $(\mathrm{RH})$, and particle light scattering ( $\mathrm{B}_{\text {sp }}$; also used as a proxy for real-time $\mathrm{PM}_{2.5}$ mass concentration) with a laser photometer (optical wavelength, $\lambda$ $=635 \mathrm{~nm}$ ). Real-time STEMS data were logged via a laptop. Integrated filter samples were collected on two $47 \mathrm{~mm}$ diameter filter trains with equal flows for gravimetric and thermo-optical OC/EC Analysis (see the SI for details). One of the filter trains contained a quartz filter, and the other contained a Teflon filter followed by a backup quartz filter downstream to correct for gas 

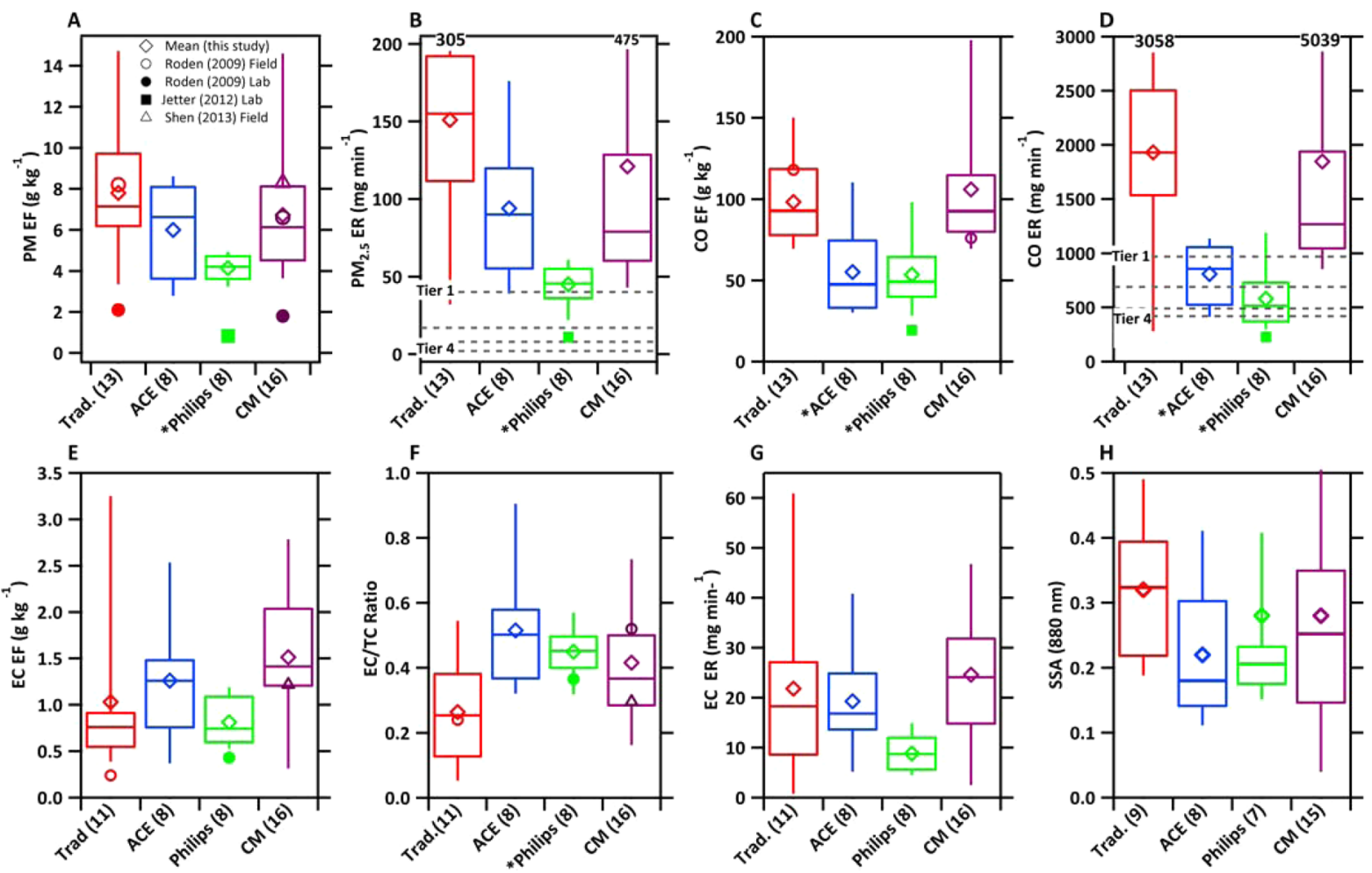

Figure 1. Box plots of pollutant emission factors (in $\mathrm{g} \mathrm{kg}^{-1}$ ) and emission rates (in $\mathrm{mg} \mathrm{min}^{-1}$ ), with the number of tests of each type indicated in the axis label. Boxes represent interquartile range, whiskers indicate 5th and 95th percentiles, and the horizontal line in the box is the median. 95th percentile whiskers for some of the cookstoves were out of scale on the $y$ axis and are indicated by numbers on the top axis. Panel A: PM ${ }_{2.5} \mathrm{EF} \mathrm{Panel}$ B: CO EF; Panel C: PM ER, Panel D: CO ER; Panel E: EC EF; Panel F: EC ER; Panel G: EC/TC ratio; Panel H: single scattering albedo at 880 $\mathrm{nm}$. Tier values for panels C and D were taken from ISO IWA 11:2012 Guidelines. ${ }^{17}$ The legend for all panels is in panel A. An asterisk before the stove name on the lower axis indicates a statistically significant difference with respect to traditional stoves $(p<0.05)$. Data from Shen et al. ${ }^{21}$ is for a movable metal cookstove used in China. Data from Roden et al. $(2006)^{47}$ is for an improved Patsari cookstove.

phase absorption artifacts. ${ }^{45}$ Additional details on the STEMS sensors, filter analysis and associated uncertainties, and quality assurance are provided in Section S1 in the SI.

Real-time PM light absorption at $\lambda=880 \mathrm{~nm}$ was measured using an AE-51 MicroAeth (AethLabs) incorporated within STEMS. To avoid excessive filter loadings and frequent filter ticket changes in the field, an external flow meter (Honeywell AWM $3150 \mathrm{~V}$ ) and vacuum source were used in place of the internal pump and flow rate set at $10-25 \mathrm{~cm}^{3} \mathrm{~min}^{-1}$. The MicroAeth filter loading artifact was corrected via the algorithm described by Park et al. ${ }^{46}$ Additional details are described in SI Section S2.

A six-armed stainless-steel probe with sampling ports radially centered in equal areas was used to capture a representative sample of naturally diluted emissions approximately $1-1.5 \mathrm{~m}$ above the cookstove. ${ }^{47}$ From the probe, emissions passed through conductive sampling tubing to the STEMS via a 2.5 $\mu \mathrm{m}$ cut-point cyclone (BGI Inc.). Background air was sampled for 5-10 min before and/or after each cooking session. Wood fuel was set aside before the start of cooking and wood moisture and weight recorded as per the KPT protocol. ${ }^{35}$ Wood moisture content was measured with an electronic moisture meter (Lignomat mini-Ligno S/DC). Wood weight before and after cooking were used to determine wood consumed. The fire was started using matches or hot charcoal left from a previous cooking session; the latter practice was more common. It was not feasible to weigh starting or leftover char during the study. One kg of wood can result in up to $161 \mathrm{~g}$ of char being formed. ${ }^{48}$ Neglecting starting char likely biases high the estimates of wood consumed, whereas neglecting leftover char results in a low bias to wood consumed. To account for this, we assume a conservative $20 \%$ uncertainty in wood consumed. A brief, anonymous survey was conducted after testing to collect user feedback on performance and perception of alternative cookstoves.

2.3. Emission Factor and Emission Rate calculations. Fuel based emissions factors were calculated using the carbon balance method, assuming that carbon comprises 50\% of dry wood by weight and all gaseous carbon in the wood is emitted as $\mathrm{CO}$ and $\mathrm{CO}_{2}$. Since the summed carbon mass obtained from background-corrected $\mathrm{CO}$ and $\mathrm{CO}_{2}$ concentrations serves as a tracer for the fuel consumed, the carbon balance does not require all emissions to be captured. Other carbonaceous species (e.g., gaseous hydrocarbons) contribute a relatively small fraction $(<5 \%)$ of carbon in emissions and are neglected in this calculation. ${ }^{21,22,47,49}$ Additional details on EF and ER calculations and associated uncertainties are described in SI Section S3.

\section{RESULTS AND DISCUSSION}

3.1. Pollutant Emission Factors and Emission Rates. 45 household cooking sessions were measured, with durations from 19 to $233 \mathrm{~min}$ (median $=49 \mathrm{~min}$ ) across 4 cookstove technologies (Traditional, Philips, ACE-1 and CM) in 22 households, with two tests (in some cases with different cookstoves) conducted in each household wherever possible. Axis labels in Figure 1 indicate the number of tests of individual cookstove types; cookstove-type, household identifier, and 
Table 1. Food and Fuel Based Emission Factors for Institutional Cookstoves ${ }^{a}$

\begin{tabular}{|c|c|c|c|c|c|c|c|}
\hline \multirow[b]{2}{*}{ cookstove } & \multicolumn{4}{|c|}{ fuel based EF ( $\mathrm{g} / \mathrm{kg}$ fuel) } & \multicolumn{3}{|c|}{ food based EF ( $\mathrm{g} / \mathrm{kg}$ food) } \\
\hline & $\mathrm{CO} \mathrm{EF}$ & PM EF & EC EF & $\mathrm{EC} / \mathrm{TC}$ & $\mathrm{CO} \mathrm{EF}$ & PM EF & EC EF \\
\hline $\operatorname{TSF}(N=3)$ & $105(9)$ & $7.1(1.3)$ & $0.58(0.21)$ & $0.18(0.07)$ & $7.9(1.4)$ & $0.53(1.11)$ & $0.042(0.010)$ \\
\hline Aleva $(N=1)$ & 43 & 3.5 & 0.35 & 0.25 & 4.7 & 0.40 & 0.038 \\
\hline Mayankho $(N=3)$ & $33(15)$ & $2.4(0.6)$ & $0.73(0.23)$ & $0.61(0.23)$ & $2.21(0.98)$ & $0.16(0.04)$ & $0.049(0.017)$ \\
\hline Jumbozama $(N=3)$ & $29(13)$ & $1.8(0.5)$ & $0.5(0.36)$ & $0.45(0.24)$ & $1.5(0.8)$ & $0.09(0.03)$ & $0.024(0.013)$ \\
\hline
\end{tabular}

${ }^{a}$ Values are averages and numbers in brackets are sample standard deviations.

emissions data from all tests are listed in Table S5. Wood moisture ranged from 6 to $26 \%$ for all sessions and was not significantly different for tests of different cookstoves. Figure $1 \mathrm{~A}$ shows distributions of $\mathrm{PM}_{2.5}$ EFs for each cookstove model. Traditional cookstoves had the highest PM EF of $7.8 \pm 2.9 \mathrm{~g}$ $\mathrm{kg}^{-1}$ (average $\pm \mathrm{SD}$ ), similar to field observations in Honduras, ${ }^{47}$ while Philips had the lowest $\left(4.1 \pm 0.6 \mathrm{~g} \mathrm{~kg}^{-1}\right)$, with $47 \%$ lower mean emissions than the traditional stove, a statistically significant reduction $(p<0.005$ from two-sample $t$ test). Mean CM and ACE-1 EFs were lower than that from traditional stoves but not significantly so $(p=0.347$ and 0.158 , respectively). Linear regressions showed no relationship between fuel moisture content and PM EF for individual cookstove types $\left(R^{2}<0.1\right.$ for all $)$.

CO EFs (Figure 1B) measured ranged from 28 to $198 \mathrm{~g} \mathrm{~kg}^{-1}$, with traditional stoves the highest $\left(98 \pm 26 \mathrm{~g} \mathrm{~kg}^{-1}\right)$, comparable to field measurements from traditional open fires in Honduras $\left(116 \pm 55 \mathrm{~g} \mathrm{~kg}^{-1}\right){ }^{47}$ Both FDCS models had statistically significant reductions of $45 \%(p<0.005)$. The mean CO EF for CM was $106 \mathrm{~g} \mathrm{~kg}^{-1}$, not significantly different from traditional stoves $(p=0.507)$.

Although these EFs are similar to those from other field studies, they are considerably higher than those observed in laboratory tests. Mean $\mathrm{PM}_{2.5} \mathrm{EF}$ for traditional stoves is roughly 3.7 times higher than laboratory tests. ${ }^{20}$ For the Philips, laboratory mean $\mathrm{PM}_{2.5}$ and $\mathrm{CO} \mathrm{EFs}$ were 80 and $65 \%$ lower than our mean values, respectively. ${ }^{50}$ Estimated uncertainties in our PM EF values are $10-30 \%$, with an average uncertainty of $15 \%$ (SI Section S3), smaller than variability in EF values within groups (e.g., PM EF coefficient of variation ranges from $14 \%$ for Philips to $44 \%$ for CM).

Fuel based EFs do not account for two parameters important for understanding total emissions: cooking time and wood consumed, which depend on cooking activity and cookstove efficiency. Here we account for these factors by estimating ERs using measured fuel use. Figure S5 in the Supporting Information shows a box-whisker plot of wet-basis (as measured) wood consumption rate in $\mathrm{kg} \mathrm{h}^{-1}$. Traditional stoves had the highest fuel consumption rate; mean reductions from the CM, ACE, and Philips were $26 \%, 27 \%$, and $51 \%$, respectively. Observed reductions are consistent with, but slightly smaller than, reductions in WBT fuel consumption observed during tests of the CM (33\%) and Philips (61\%) in Malawi. $^{51}$

Figure $1 \mathrm{C}$ and $1 \mathrm{D}$ show the PM and CO ERs estimated using measured fuel values (on a dry fuel basis); also shown are tier boundaries for indoor emission rates. ${ }^{17}$ The trend is generally similar to that seen for EFs. The Philips shows reductions of both $\mathrm{PM}_{2.5}$ and $\mathrm{CO}$ ERs by $70 \%$ compared to traditional stoves. However, PM and CO ERs based on laboratory testing of Philips cookstove (for wet wood) are 76 and $61 \%$, respectively, lower than our mean values. ${ }^{50}$ This indicates that laboratory tests may substantially underestimate real-world emissions of even the most advanced wood-burning cookstoves when fuel properties and cookstove operation are variable.

Figures $1 \mathrm{E}$ to $1 \mathrm{G}$ show box plots of EC EFs, ERs, and EC/ $\mathrm{TC}$, respectively, where TC is total carbon $(\mathrm{OC}+\mathrm{EC})$. All quantities show high variability due to the uncontrolled nature of this combustion and varying usage and fueling of the cookstoves and skill of the cook. EC EFs and EC/TC ratios for intervention cookstoves are generally higher than those for traditional stoves, though only the Philips shows a significant difference for EC/TC. Increases are moderated for ERs due to reduced fuel use, especially for the Philips cookstove. EC EFs for CM were similar to observations for basic "improved" cookstoves in other field studies. ${ }^{20,21}$ FDCSs had the highest EC/TC ratios (0.48) followed by CM (0.42) and TSF (0.28). $\mathrm{EC} / \mathrm{TC}$ is typically $\sim 0.1^{52}$ for open biomass burning, significantly lower than values observed in this study. This highlights that combustion under these relatively controlled conditions emits particles with distinct properties compared to those from open biomass burning. Additional discussion on $\mathrm{EC} / \mathrm{TC}$ ratios and SSA is provided in Section 3.3. A summary of EFs and optical properties for each test is provided in SI Table S5.

3.2. Institutional Cookstoves - Food and Fuel Based Pollutant Emission Factors. Ten CCTs on four institutional cookstove configurations were completed. Food- and fuel-based EFs for institutional cookstoves are reported in Table 1. EFs for $\mathrm{PM}$ and $\mathrm{CO}$ followed a consistent trend, with the I-TSF the highest, followed by the AL, MA, and JZ. CO and PM emissions were reduced by similar amounts, with CO (PM) emissions reduced by $67 \%$ (68\%) and $73 \%$ (75\%) for MA and JZ, respectively. Averaged wood consumption rate was highest for the Aleva $\left(5.2 \mathrm{~kg} \mathrm{~h}^{-1}\right)$, followed by I-TSF $\left(4.18 \mathrm{~kg} \mathrm{~h}^{-1}\right)$, Mayankho $\left(3.85 \mathrm{~kg} \mathrm{~h}^{-1}\right)$, and JumboZama $\left(3.30 \mathrm{~kg} \mathrm{~h}^{-1}\right)$. EC/ TC generally increased for alternative cookstoves relative to ITSF. Food based PM and CO EFs follow the same trend as their fuel based counterparts, with JZ exhibiting $>80 \%$ reductions for both. The JZ cookstove used a slightly smaller, different cooking pot ( $80 \mathrm{~L}$ vs $100 \mathrm{~L}$ for other cookstoves), which may have contributed to mean PM EF values (e.g., due to a quicker warm-up phase) and cooking times that were $61 \%$ and $32 \%$ lower, respectively, than those for other cookstoves. Further extensive comparisons of these data are complicated by the small sample size and lack of emission data in the literature. SI Table S6 summarizes all institutional cookstove tests.

3.3. Real-Time Optical Properties. Figure S6 in the SI shows real-time ( $2 \mathrm{~s}$ and $1 \mathrm{~min}$ average) concentrations of $\mathrm{CO}$, $\mathrm{CO}_{2}$, particle absorption, and scattering coefficients $\left(\mathrm{B}_{\mathrm{ap}} ; \mathrm{B}_{\mathrm{sp}}\right)$ for representative FDCS and traditional household stove tests. Gravimetric $\mathrm{PM}_{2.5}$ concentrations correlated well $\left(R^{2}=0.87\right)$ with averaged $B_{s p}$, suggesting that real-time scattering was a reasonable proxy for real-time $\mathrm{PM}_{2.5}$ mass concentrations under these test conditions (SI Figure S7). 
a) Traditional Stoves ( $N=9$ )

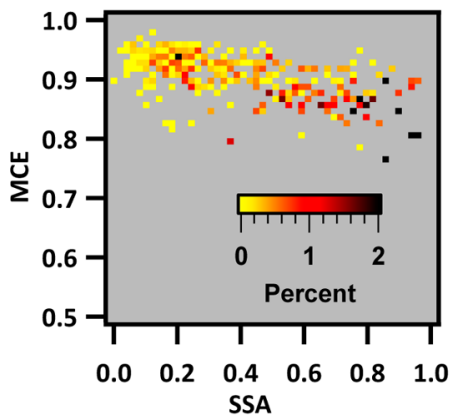

b) Chitetezo Mbaula ( $\mathrm{N}=16)$

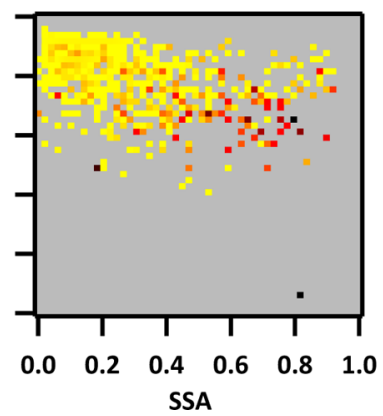

c) Forced Draft Stoves $(\mathrm{N}=14)$

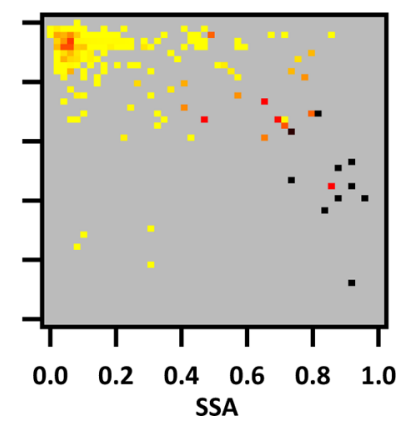

Figure 2. Bivariate histogram of MCE and SSA weighted by particle emissions (PaRTED plots) for a. Traditional; b. Chititezo Mbaula, and c. FDCS. The bottom axis delineates bins of single scattering albedo (SSA) at $880 \mathrm{~nm}$, and the left axis shows modified combustion efficiency (MCE) bins. $N$ indicates the number of tests included for this analyses. Each location on the plot represents an SSA and MCE at which a combustion event ( 1 min) may occur; the color scale indicates the percent contribution of emissions at that condition to the total scattering ( PM mass) emitted. Three of the traditional stove tests were excluded from this analysis due to lack of either $\mathrm{CO}_{2}(1$ test) or absorption data ( 2 tests).

Figure S6 also shows single scattering albedo (SSA; fraction of scattering to total extinction; $\left(\mathrm{B}_{\mathrm{sp}} /\left(\mathrm{B}_{\mathrm{ap}}+\mathrm{B}_{\mathrm{sp}}\right)\right.$, here at $\lambda=880$ $\mathrm{nm})$ and modified combustion efficiency (MCE; $\Delta \mathrm{CO}_{2} /(\Delta \mathrm{CO}$ $\left.+\Delta \mathrm{CO}_{2}\right)$, where $\Delta$ indicates background-corrected concentrations in ppm). A lower SSA signifies a greater contribution from absorption to total aerosol light extinction, while higher MCEs indicate more efficient combustion. All cooking events were characterized by a scattering spike at startup ${ }^{47}$ (evident in Figure S6). Observations of cooking activity showed that addition and adjustment of fuel typically resulted in spikes in $\mathrm{B}_{\text {ap }}$ for FDCS and in $\mathrm{B}_{\mathrm{sp}}$ for traditional stove tests. FDCS tests typically had a large scattering peak only at startup and overall particle extinction was dominated by absorption, while extinction from traditional stove tests was dominated by scattering. As a result, traditional stove tests had comparatively higher SSA (shown in Figure $1 \mathrm{H}$ ) and lower MCE than FDCS tests. Test-average SSA was highest for Traditional stoves (0.36), followed by CM (0.28) and FDCS (0.25); particles from all "alternative" cookstoves are more absorbing than those from traditional stoves and thus have greater specific warming.

Our optical measurements are at $\lambda=880 \mathrm{~nm}$, which influences the quantities (e.g., SSA) presented here, but likely not the relative trends discussed here and below. For example, while SSA for pure BC aerosol is typically $0.15-0.3$ at $\lambda=530$ $\mathrm{nm},{ }^{47}$ we observe periods with SSA ranging from $\sim 0-0.2$ for FDCS, despite the fact that the particles are not pure BC. Section S5 and Figure S8 in the SI present Mie theory modeling indicating that both the longer wavelength and smaller particle diameter in FDCS emissions likely strongly reduces the scattering efficiency of these particles. The average mass scattering cross section (MSC; ratio of scattering to gravimetric $\mathrm{PM}_{2.5}$ concentration) over all tests was $0.87 \pm 0.31$ $\mathrm{m}^{2} \mathrm{~g}^{-1}$, substantially lower than MSCs of $3.6-4.3 \mathrm{~m}^{2} \mathrm{~g}^{-1}(\lambda=$ $550 \mathrm{~nm})$ and $2.2 \pm 0.6 \mathrm{~m}^{2} \mathrm{~g}^{-1}(\lambda=530 \mathrm{~nm})$ reported for emissions from dry biomass burning and in-field cookstoves, respectively. ${ }^{47}$ Lower MSC values in our study are consistent with the wavelength dependence of scattering. Averaged mass absorption cross-section (MAC; ratio of $B_{\text {ap }}$ to EC concentration) for all tests was $13.2 \pm 4.8 \mathrm{~m}^{2} \mathrm{~g}^{-1}$, overlapping with the MAC of $12.5 \mathrm{~m}^{2} \mathrm{~g}^{-1}$ assumed in the microAethalometer. ${ }^{53}$

The data show a general trend of decreasing SSA with increased MCE and EC/TC. SI Figure S9 shows the relationships between $\mathrm{MCE}$ and EC/TC with SSA for inhome cookstove testing. Greater specific absorption correlates somewhat with higher MCE $\left(R^{2}=0.29\right)$ and more strongly with higher EC/TC $\left(R^{2}=0.57\right)$. This general trend is also evident in Figures $1 \mathrm{G}$ and $1 \mathrm{H}$. These relations are consistent with greater $\mathrm{BC}$ production in more efficient, contained combustion where MCE is highest, while more scattering OC is produced during less efficient (perhaps lower temperature) combustion. Relationships between MCE, EC/TC, and SSA have been proposed based on measurements of open biomass burning for a range of fuels. ${ }^{54,55}$ While the general trends we observe are consistent with the published parametrizations, a direct comparison is not possible due to differences in measurement wavelength. However, it is likely that the relationships would be different because combustion technology strongly influences aerosol properties.

Test-average quantities do not reflect the contribution of distinct combustion phases to total emissions. Analysis of realtime data can give insight into the variation of parameters such as MCE and particle properties throughout a burn. We incorporated the 'Patterns of Real-Time Emissions Data' (PaRTED) analysis approach of Chen et al. ${ }^{56}$ to evaluate quantities and optical characteristics of emissions based on realtime data. In this analysis, MCE and SSA are calculated for each minute of data (termed a combustion event). A bivariate histogram of MCE and SSA, weighted by instantaneous scattering emission factor ( $\mathrm{IEF}_{\text {scat, }}$ particle light scattering normalized by mass of fuel consumed) and normalized by total scattering emissions, is then constructed. The resulting plot shows the fractional contribution of combustion at specific conditions (MCE; SSA) toward total scattering emissions. This weighting is chosen to represent the distribution of total particle emissions, as scattering shows a strong correlation $\left(R^{2}\right.$ $=0.87$ ) with $\mathrm{PM}_{2.5}$ from gravimetric analysis (Figure S5). Additional information on this approach can be found in SI Section S4.

Figure 2 shows PaRTED plots for traditional, CM, and FDCS (ACE-1 and Philips combined) emission tests, with each panel representing all test data from that cookstove type. The three cookstove types show distinct patterns with some common features. All display a cluster at MCE > 0.9 and SSA $<0.4$, suggesting that all produce more absorbing particles during more efficient flaming combustion. However, all test types also had combustion events and particle emissions at lower MCE and higher SSA, with noticeably more spread in this direction among the traditional cookstove and CM tests. 
The FDCS plot shows a more distinct and concentrated cluster at high MCE, low SSA. Figure S10 in the SI shows histograms weighted with fuel consumption (calculated as $\Delta \mathrm{CO}+\Delta \mathrm{CO}_{2}$ ) rather than particle scattering and shows that the vast majority of $f$ uel consumption occurs at high MCE/low SSA ( $88 \%$ at MCE $>0.9$ and SSA $<0.4$ for FDCS), whereas only $12 \%$ of scattering emissions took place under these conditions. The corresponding fractions (fuel consumption/scattering) in this MCE-SSA range are $57 \% / 15 \%$ and $58 \% / 25 \%$ for the $\mathrm{CM}$ and Traditional tests, respectively. This reinforces that the relative distribution of combustion conditions varies between stoves and has substantial impacts on particle emissions and properties. The events with high scattering contributions at lower MCE are "rare" (though less so for Traditional/CM tests) but emit a large fraction of scattering particles/particle mass. Time series data (Figure S6) show that all tests had sharp peaks in scattering emissions during cookstove startup, consistent with other field measurements. ${ }^{20}$ The PaRTED plots also suggest that these startup emissions may make outsized contributions to overall PM emissions. We examine the contribution of startup emissions in SI Figure S11, which plots the running average of $\mathrm{IEF}_{\text {scat }}$ against normalized time for each test of a cookstove type. In all tests, the average peaks strongly during the startup phase, confirming the importance of start emissions. Although the test averaged $\mathrm{IEF}_{\text {scat }}$ (at the right edge of the graph) is highest for Traditional and lowest for FDCS tests, we see a much higher peak for gasifiers and in nearly all cases a monotonic decrease in $\mathrm{IEF}_{\text {scat }}$ during the test, reinforcing the dominance of startup emissions for these cookstoves. The outsized contribution of startup to PM emissions from FDCS has important implications for exposure as during startup the cook is assured to be in close proximity to the cookstove.

3.4. Climate/Health "Cobenefits" of Different Cookstove Options. 100- and 20-year GWC (tons of $\mathrm{CO}_{2}$ equivalent per year of cookstove use) were estimated based on measured pollutant emission factors $\left(\mathrm{CO}_{2}, \mathrm{CO}, \mathrm{OC}\right.$, and $\left.\mathrm{EC}\right)$ for household and institutional cookstoves following the approach of previous work, ${ }^{16}$ as briefly discussed in SI section S6. GWCs associated with the use of a modern fuel, LPG, are also included as a benchmark (based on laboratory EFs). The Intergovernmental Panel on Climate Change (IPCC) default value of 0.81 for the fraction of nonrenewable biomass (fNRB) in Malawi $^{57}$ was assumed for all calculations, though this is highly uncertain due to factors including spatial heterogeneity in $\mathrm{ANRB}$ and uncertainties in data on fuel demand and its dynamics. ${ }^{58}$ A fixed energy demand was assumed and annual fuel use for each cookstove estimated based on fuel use rate reductions observed in this study (Figure S5) relative to the baseline (Traditional cookstoves). GWC calculations used global warming potential (GWP) values recommended by the Gold Standard Foundation and IPCC ${ }^{59}$ and account only for emissions during fuel combustion. GWC associated with upstream processes (e.g., fuel production and transport) related to cookstove fuel use have been found to be negligible for woodfuel and relatively small (10-20\% of combustion stage) for $\mathrm{LPG}^{60}{ }^{60}$ though they may be considerable for other fuels such as coal or charcoal. ${ }^{16} \mathrm{CH}_{4}$ makes a substantial contribution to the GWC associated with cookstove use ${ }^{16,22}$ but was not measured here. To approximate $\mathrm{CH}_{4}$ GWC, $\mathrm{CH}_{4}$ : $\mathrm{CO}$ ratios from the literature ${ }^{16,50}$ were used to estimate $\mathrm{CH}_{4}$ EFs; $\mathrm{CH}_{4}$ : $\mathrm{CO}$ ratios of 0.05 for ACE- 1 and Philips and 0.08 for the Traditional, CM, and Institutional cookstoves were used in calculations. GWC contributions from other hydro- carbons and $\mathrm{N}_{2} \mathrm{O}$ are small for biomass emissions ${ }^{22,48,61}$ and are neglected here. Also not included in this accounting is brown carbon $(\mathrm{BrC})$, the component of OC that absorbs energy across visible and ultraviolet wavelengths. We did not measure absorption at multiple wavelengths in this work but expect that the $\mathrm{BrC}$ absorption would make a relatively small contribution to short-wavelength absorption considering the very high EC:OC ratios (mean for all tests was $\sim 1$ ) observed in emissions from all cookstoves. $\mathrm{BrC}$ is expected to have little additional impact on climate forcing for emissions with EC:OC ratios above $0.1,9$ though this merits further study.

Figure 3 shows the GWC values estimated across a 100-year horizon (Figure S12 shows 20 year GWCs). As expected,

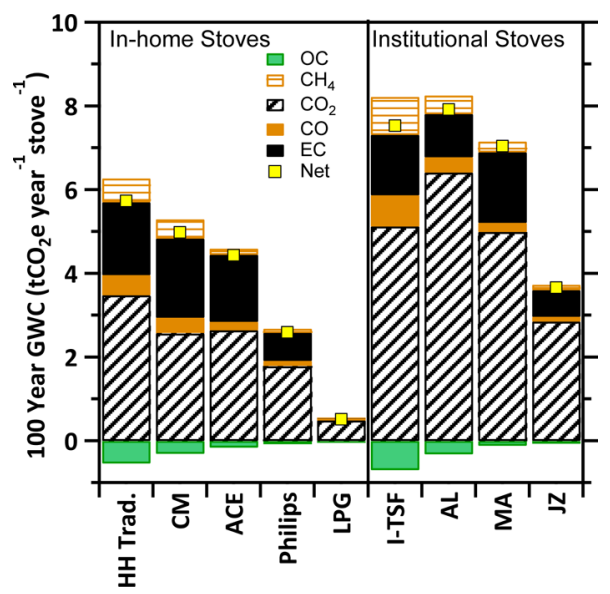

Figure 3. 100 year GWC values for one year of use of in-home cookstoves (L) and institutional cookstoves (R) from major short- and long-lived climate forcing species emitted by cookstoves. The $\mathrm{CH}_{4}$ component is estimated based on the $\mathrm{CH}_{4}: \mathrm{CO}$ ratio from other studies. Note that the daily energy use is different for household and institutional cookstoves. In-home cookstoves are assumed to be used every day of the year. Institutional cookstoves are assumed to be used for twice a day for 5 days a week for 40 weeks a year with an energy basis based on average fuel use measured in this study.

traditional cookstoves show the highest GWC, followed by the CM, ACE, and Philips. Across a 100 year horizon for household cookstoves, CM, ACE, and Philips show overall reductions of $13 \%, 23 \%$, and $55 \%$, respectively, from the household traditional (HH-Trad) stoves. Across household stove models, the highest relative contribution by species is from $\mathrm{CO}_{2}(51-$ $69 \%)$ followed by EC $(26-38 \%)$ with other species contributing less than $10 \%$. Calculations using laboratory EFs suggest much larger reductions (59\% and 93\% for improved and FDCS, respectively) relative to traditional stoves, ${ }^{16}$ highlighting again the implications of the lab-field discrepancy in emissions. Due to high combustion efficiency for LPG, PICs contribute minimally to its GWC, and the vast majority is contributed by $\mathrm{CO}_{2}$. The GWC of LPG is a factor of 4 lower than the cleanest cookstove tested in the field (Philips). Among institutional cookstoves, only the JZ yielded substantial fuel use and emission reductions during our limited testing, leading to an $\sim 50 \%$ reduction in GWC relative to baseline. Across a $20-$ year horizon (Figure S12) EC contributes the most to biomass cookstove GWC, contributing 53-65\% across all cookstoves.

Figure 4 combines GWC estimates with those for human exposure to $\mathrm{PM}_{2.5}$ to examine the cookstoves measured in a "cobenefits" framework. The exposure estimation applies an individual intake fraction of $1300 \mathrm{ppm}(1 \mathrm{ppm}=1 \mathrm{mg}$ inhaled 


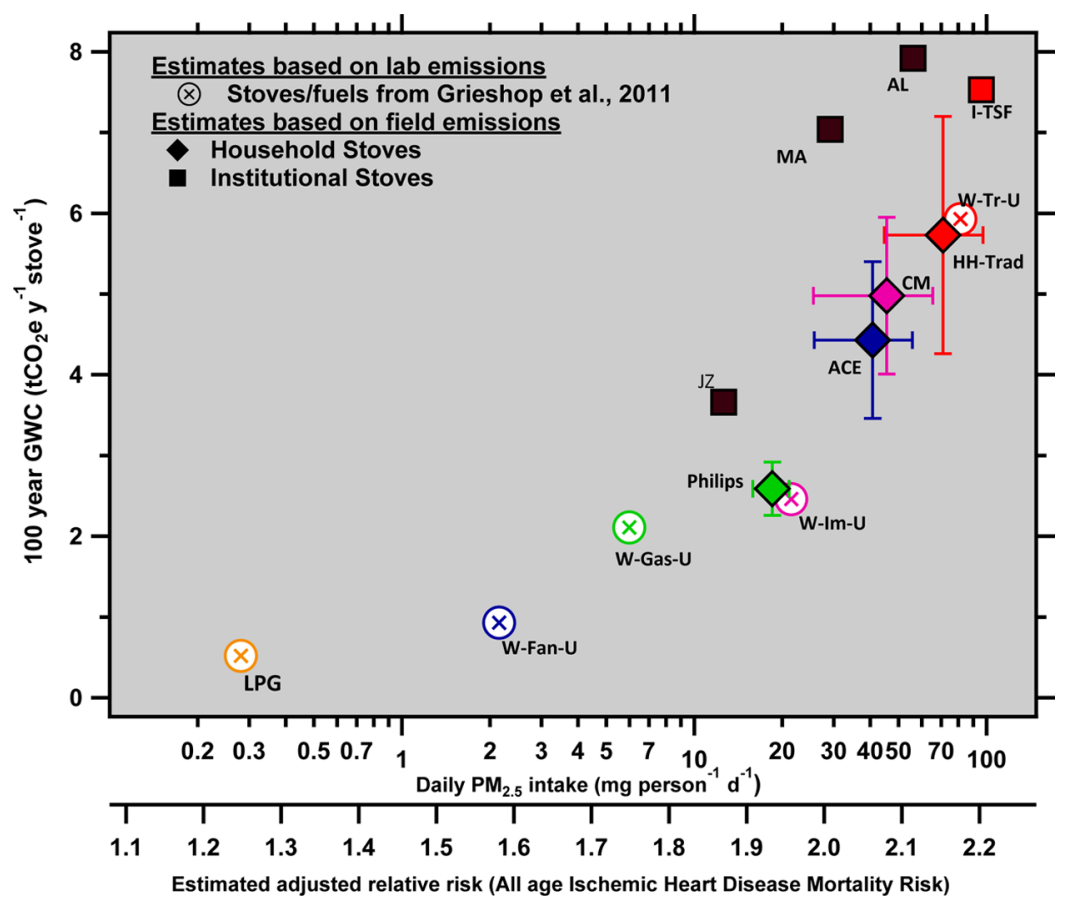

Figure 4. Health and climate impacts of various cookstove-fuel combinations based on laboratory emission test data (shown with circles; adapted from Grieshop et al. ${ }^{16}$ with fuel renewability and energy demand values described in text) along with the estimates from this study are shown, marked with diamonds and squares with error bars for in-home and institutional cookstoves, respectively. Abbreviations for laboratory-based calculations: W-Tr-U: Wood-burning traditional unvented cookstoves; W-Im-U: Wood-burning improved unvented cookstoves; W-Gas-U: Woodburning gasifier unvented cookstoves; W-Fan-U: Wood-burning fan unvented cookstove. Abbreviations for field-based calculations: HH-Trad.: Household Traditional; CM: Chitetezo Mbaula; Philips: Philips HD4012LS; ACE: ACE-1; I-TSF: Institutional three stone fire; AL: Aleva; MA: Mayankho; JZ: Jumbozama.

per $\mathrm{kg}$ emitted) to link emissions to human exposure. ${ }^{16}$ The figure shows estimated daily PM intake (horizontal axis) and GWC (vertical axis) of several cookstove technologies evaluated in that study, ${ }^{16}$ with added estimates made based on data from in-home testing during this study. It should be noted these calculations assume complete adoption of the cookstove in question, while field trials have shown that new technologies are rarely used exclusively and "stove stacking" is the norm. ${ }^{30,62,63}$ These values thus represent "best-case" scenarios. The exposure-response relationship for all-age mortality risk from ischemic heart disease (IHD) from Burnett et al. ${ }^{64}$ is used to estimate adjusted relative risk of mortality due to IHD (dose-response for chronic obstructive pulmonary disease mortality is similar), shown on the lower horizontal axis. This extrapolation of our field emissions data suggests that the Philips cookstove reduces PM emissions and intake by approximately $75 \%$ relative to the traditional stove; this is associated with a smaller reduction in estimated mortality relative risk (from 2.2 to 1.9 ) due to the nonlinear doseresponse relationship. ${ }^{64}$ This figure dramatically demonstrates the implications of the performance decrement observed in field measurements. Field-tested biomass stoves do not meet expectations based on laboratory tests in terms of emissions/ exposure. For example, relative to estimates based on laboratory measurements, the field-measurement-based daily PM intake and GWC for the Philips are a factor of 8.6 and 2.8 times higher, respectively. The Philips and JZ have the lowest estimated intake and GWC among in-home and institutional cookstoves, respectively, but are still associated with far greater impacts than the "benchmark" LPG cookstoves. For example, compared to the estimated impacts of LPG cookstove use, in- home use of a Philips cookstove results in 4.9 times higher GWC and around 66 times higher daily exposure, corresponding to increase in adjusted relative risk for IHD mortality from 1.25 to 1.95 . Impact estimates for $\mathrm{HH}$-Trad, CM, and three of the institutional cookstoves (I-TSF, MA, and AL) are within the bounds of impact estimates for laboratory-tested traditional stoves, whereas the best performing FDCS is in the range estimated based on laboratory performance of a basic improved biomass cookstove ( $\mathrm{W}-\mathrm{Im}-\mathrm{U})$. Field observations of emissions from a range of cookstoves used in interventions give important insights into the potential for these technologies to mitigate the health and climate impacts associated with traditional cookstoves.

\section{IMPLICATIONS}

Our results suggest that both simple "improved" cookstoves and more advanced biomass cookstoves provide some benefits but fall short of those indicated by laboratory testing or that may be possible through the use of modern fuels/devices. Impact estimates shown here (Figure 4) are rough approximations but are consistent with field trials that have seen less than expected benefits from cookstove interventions. ${ }^{30,42,65,66}$ For example, the fact that no effect on childhood pneumonia incidence was observed during CAPS $^{42}$ may be partly due to poorer-than-expected performance of these cookstoves under real-world conditions; other factors such as continued use of traditional stoves and exposure to air pollution from other sources likely also contributed to this outcome. Forthcoming findings from other intervention trials will report on the health effects associated with other fuel/cookstove technologies 
including LPG and give insights into whether or not they provide the benefits that might be predicted. ${ }^{67,68}$

A range of factors contribute to reduced performance observed in the field, all related to the difficulty of controlling combustion of heterogeneous fuels under widely ranging conditions. Part of the performance decrement observed is due to cookstoves not being used in accordance with manufacturer recommendations. For example, wood pieces sticking out of the top of FDCS were commonly observed in the field (Figure S1 in the SI) and lead to suboptimal combustion of the volatiles emitted from pyrolysis of wood. However, this practice is unsurprising when one considers that processing larger logs and branches to the size recommended for the FDCS models considered here $(\sim 1 \times 5 \mathrm{~cm})$ represents additional work for the household. This source of variability may be addressed via a cookstove that is highly robust to changing fuel type/configuration or a situation in which a homogenized fuel source (e.g., pellets) is provided or readily available. The former is only likely possible in a more advanced combustion device (e.g., the enclosed heating stoves, often with catalytic after treatment of exhaust used in developed countries) that are beyond the budget of the target population, while the latter requires a close look at the broader system, beyond the cookstove.

These observations highlight the need to expand the view beyond "clean cookstoves" to clean and controlled cooking systems, which could provide considerable health and climate benefits and perform consistently and reproducibly under both laboratory and field conditions. One approach advocated is to focus efforts on a switch to modern appliances (e.g., electrical induction cookers and LPG) rather than promoting "improved" biomass cookstoves, ${ }^{69}$ though such technologies would be out of reach in the short- to medium-term for the poorest of the world's poor (e.g., rural Malawians). Improvements using biomass can likely be made by improving the cookstove/fuel system in tandem.

Our findings emphasize that laboratory protocols do not fully anticipate real-world emissions when fuel properties and cookstove operation are variable and highlight the need for testing approaches that more accurately represent real-world cookstove use. Field evaluation of emissions performance early in product development would be one way to achieve this; another way would be to develop testing protocols that simulate the range of ways a cookstove may be used, including low-efficiency emissions such as smoldering, often observed in field emissions. ${ }^{56,70,71}$ These data were collected during a dry season, and fuel moisture may also have important impacts on stove performance; ${ }^{50}$ future field studies should assess stove performance across an annually representative period if possible.

\section{ASSOCIATED CONTENT}

\section{S Supporting Information}

The Supporting Information is available free of charge on the ACS Publications website at DOI: 10.1021/acs.est.6b05557.

Additional details on filter and data processing, uncertainty analysis, Mie scattering analysis, and GWC/ intake analysis; tables of information in support of analysis and emission factors from all individual tests; figures of images of cookstoves and measurement equipment, scattering calibration data, fuel use data, example real-time data, relationships between aerosol optical and mass measurements, Mie modeling results, additional PaRTED plots, and running-average EF plot (PDF)

\section{AUTHOR INFORMATION}

\section{Corresponding Author}

*Phone: +1 (919) 513-1181. Fax: +1 (919) 515-7908. E-mail: apgriesh@ncsu.edu. Corresponding author address: Department of Civil, Construction and Environmental Engineering, North Carolina State University, 431B Mann Hall, Raleigh, NC 27695-7908, USA.

ORCID ${ }^{\circ}$

Andrew P. Grieshop: 0000-0002-6470-9946

Notes

The authors declare no competing financial interest.

\section{ACKNOWLEDGMENTS}

The authors gratefully acknowledge the Global Alliance for Clean Cookstoves (GACC) for funding and Donee Alexander and Neeraja Penumetcha from GACC for helpful comments on the work. CAPS was funded by a Joint Global Health Trials Grant from the Medical Research Council, UK Department for International Development and Wellcome Trust (ref: MR/ K006533/1) and a New Investigator Research Grant from the Medical Research Council (ref: MR/L002515/1). We thank the staff of the Cooking and Pneumonia Study (CAPS) and Concern Universal (CU) and the Malawian communities for their collaboration and support, Yamungu Botha (CU), Tione Phwandaphwanda, and Mosses Kaimfa for field assistance and Megan Boland for filter analysis. We thank Dr. Pamela Jagger (University of North Carolina at Chapel Hill), Conor Fox and Cristel Cheong (Hestian, Clioma Ltd.), Christa Roth (FOOD and FUEL Consultants), Godknows Maseko (Steka), Maya Stewart (Maeve Project), and Marie Da Silva and Luc Deschamps (Jacaranda Foundation) for their input, support, and logistical help and Dr. Wu Cheng (The Hong Kong University of Science and Technology) for providing the Mie Code in Igor Pro (https://sites.google.com/site/wuchengust/ Tools/mie-scattering-tool).

\section{REFERENCES}

(1) Foell, W.; Pachauri, S.; Spreng, D.; Zerriffi, H. Household Cooking Fuels and Technologies in Developing Economies. Energy Policy 2011, 39 (12), 7487-7496.

(2) Lim, S. S.; Vos, T.; Flaxman, A. D.; Danaei, G.; Shibuya, K.; Adair-Rohani, H.; AlMazroa, M. A.; Amann, M.; Anderson, H. R.; Andrews, K. G.; et al. A Comparative Risk Assessment of Burden of Disease and Injury Attributable to 67 Risk Factors and Risk Factor Clusters in 21 Regions, 1990-2010: A Systematic Analysis for the Global Burden of Disease Study 2010. Lancet 2012, 380 (9859), 2224-2260.

(3) Rosenthal, J. The Real Challenge for Cookstoves and Health: More Evidence. EcoHealth 2015, 12 (1), 8-11.

(4) Ramanathan, V.; Carmichael, G. Global and Regional Climate Changes due to Black Carbon. Nat. Geosci. 2008, 1 (4), 221-227.

(5) Bond, T. C.; Doherty, S. J.; Fahey, D. W.; Forster, P. M.; Berntsen, T.; DeAngelo, B. J.; Flanner, M. G.; Ghan, S.; Kärcher, B.; Koch, D.; et al. Bounding the Role of Black Carbon in the Climate System: A Scientific Assessment. J. Geophys. Res. Atmospheres 2013, 118 (11), 5380-5552.

(6) Bond, T. C.; Streets, D. G.; Yarber, K. F.; Nelson, S. M.; Woo, J.H.; Klimont, Z. A Technology-Based Global Inventory of Black and Organic Carbon Emissions from Combustion. J. Geophys. Res. 2004, 109 (D14), D14203. 
(7) Bahadur, R.; Praveen, P. S.; Xu, Y.; Ramanathan, V. Solar Absorption by Elemental and Brown Carbon Determined from Spectral Observations. Proc. Natl. Acad. Sci. U. S. A. 2012, 109 (43), 17366-17371.

(8) Feng, Y.; Ramanathan, V.; Kotamarthi, V. R. Brown Carbon: A Significant Atmospheric Absorber of Solar Radiation? Atmos. Chem. Phys. 2013, 13 (17), 8607-8621.

(9) Saleh, R.; Robinson, E. S.; Tkacik, D. S.; Ahern, A. T.; Liu, S.; Aiken, A. C.; Sullivan, R. C.; Presto, A. A.; Dubey, M. K.; Yokelson, R. J.; et al. Brownness of Organics in Aerosols from Biomass Burning Linked to Their Black Carbon Content. Nat. Geosci. 2014, 7 (9), 647650.

(10) Bond, T. C.; Bhardwaj, E.; Dong, R.; Jogani, R.; Jung, S.; Roden, C.; Streets, D. G.; Trautmann, N. M. Historical Emissions of Black and Organic Carbon Aerosol from Energy-Related Combustion, 18502000. Glob. Biogeochem. Cycles 2007, 21 (2), GB2018.

(11) Koch, D.; Bond, T. C.; Streets, D.; Unger, N.; van der Werf, G. R. Global Impacts of Aerosols from Particular Source Regions and Sectors. J. Geophys. Res. 2007, 112 (D2), D02205.

(12) Lacey, F.; Henze, D. Global Climate Impacts of Country-Level Primary Carbonaceous Aerosol from Solid-Fuel Cookstove Emissions. Environ. Res. Lett. 2015, 10 (11), 114003.

(13) Kodros, J. K.; Scott, C. E.; Farina, S. C.; Lee, Y. H.; L’Orange, C.; Volckens, J.; Pierce, J. R. Uncertainties in Global Aerosols and Climate Effects due to Biofuel Emissions. Atmos. Chem. Phys. 2015, 15 (15), 8577-8596.

(14) Grieshop, A. P.; Reynolds, C. C. O.; Kandlikar, M.; Dowlatabadi, H. A Black-Carbon Mitigation Wedge. Nat. Geosci. 2009, 2 (8), 533-534.

(15) Jeuland, M. A.; Pattanayak, S. K. Benefits and Costs of Improved Cookstoves: Assessing the Implications of Variability in Health, Forest and Climate Impacts. PLoS One 2012, 7 (2), e30338.

(16) Grieshop, A. P.; Marshall, J. D.; Kandlikar, M. Health and Climate Benefits of Cookstove Replacement Options. Energy Policy 2011, 39 (12), 7530-7542.

(17) IWA, I. 11:2012: Guidelines for Evaluating Cookstove Performance; Int. Organ. Stand.: 2012.

(18) Bailis, P. R.; Ogle, D.; MacCarty, N.; Still, D.; Smith, K. R.; Edwards, R. Water Boiling Test (WBT); Prepared for the Household Energy and Health Programme, Shell Foundation, 2007.

(19) Shen, G.; Siye, W.; Wen, W.; Yanyan, Z.; Yujia, M.; Bin, W.; Rong, W.; Wei, L.; Huizhong, S.; Ye, H.; et al. Emission Factors, Size Distributions, and Emission Inventories of Carbonaceous Particulate Matter from Residential Wood Combustion in Rural China. Environ. Sci. Technol. 2012, 46 (7), 4207-4214.

(20) Roden, C. A.; Bond, T. C.; Conway, S.; Osorto Pinel, A. B.; MacCarty, N.; Still, D. Laboratory and Field Investigations of Particulate and Carbon Monoxide Emissions from Traditional and Improved Cookstoves. Atmos. Environ. 2009, 43 (6), 1170-1181.

(21) Shen, G.; Tao, S.; Wei, S.; Chen, Y.; Zhang, Y.; Shen, H.; Huang, Y.; Zhu, D.; Yuan, C.; Wang, H.; et al. Field Measurement of Emission Factors of PM, EC, OC, Parent, Nitro-, and Oxy- Polycyclic Aromatic Hydrocarbons for Residential Briquette, Coal Cake, and Wood in Rural Shanxi, China. Environ. Sci. Technol. 2013, 47 (6), 2998-3005.

(22) Johnson, M.; Edwards, R.; Alatorre Frenk, C.; Masera, O. InField Greenhouse Gas Emissions from Cookstoves in Rural Mexican Households. Atmos. Environ. 2008, 42 (6), 1206-1222.

(23) MacCarty, N.; Ogle, D.; Still, D.; Bond, T.; Roden, C. A Laboratory Comparison of the Global Warming Impact of Five Major Types of Biomass Cooking Stoves. Energy Sustainable Dev. 2008, 12 (2), 56-65.

(24) Jetter, J. J.; Kariher, P. Solid-Fuel Household Cook Stoves: Characterization of Performance and Emissions. Biomass Bioenergy 2009, 33 (2), 294-305.

(25) Kar, A.; Rehman, I. H.; Burney, J.; Puppala, S. P.; Suresh, R.; Singh, L.; Singh, V. K.; Ahmed, T.; Ramanathan, N.; Ramanathan, V. Real-Time Assessment of Black Carbon Pollution in Indian House- holds Due to Traditional and Improved Biomass Cookstoves. Environ. Sci. Technol. 2012, 46 (5), 2993-3000.

(26) Patange, O. S.; Ramanathan, N.; Rehman, I. H.; Tripathi, S. N.; Misra, A.; Kar, A.; Graham, E.; Singh, L.; Bahadur, R.; Ramanathan, V. Reductions in Indoor Black Carbon Concentrations from Improved Biomass Stoves in Rural India. Environ. Sci. Technol. 2015, 49 (7), $4749-4756$

(27) Smith, K. R.; Haigler, E. Co-Benefits of Climate Mitigation and Health Protection in Energy Systems: Scoping Methods. Annu. Rev. Public Health 2008, 29, 11-25.

(28) Sanford, L.; Burney, J. Cookstoves Illustrate the Need for a Comprehensive Carbon Market. Environ. Res. Lett. 2015, 10 (8), 084026.

(29) Lee, C. M.; Chandler, C. Assessing the Climate Impacts of Cookstove Projects: Issues in Emissions Accounting. Chall. Sustain. 2014, 1 (2), 53-71.

(30) Aung, T. W.; Jain, G.; Sethuraman, K.; Baumgartner, J.; Reynolds, C.; Grieshop, A. P.; Marshall, J. D.; Brauer, M. Health and Climate-Relevant Pollutant Concentrations from a Carbon-Finance Approved Cookstove Intervention in Rural India. Environ. Sci. Technol. 2016, 50 (13), 7228-7238.

(31) Freeman, O. E.; Zerriffi, H. How You Count Carbon Matters: Implications of Differing Cookstove Carbon Credit Methodologies for Climate and Development Cobenefits. Environ. Sci. Technol. 2014, 48 (24), 14112-14120.

(32) Bond, T. C. Can Warming Particles Enter Global Climate Discussions? Environ. Res. Lett. 2007, 2 (4), 045030.

(33) Unger, N.; Bond, T. C.; Wang, J. S.; Koch, D. M.; Menon, S.; Shindell, D. T.; Bauer, S. Attribution of Climate Forcing to Economic Sectors. Proc. Natl. Acad. Sci. U. S. A. 2010, 107 (8), 3382-3387.

(34) Black Carbon and other Short-Lived Climate Pollutants I The Gold Standard. http://www.goldstandard.org/articles/black-carbonand-other-short-lived-climate-pollutants (accessed Jul 12, 2016).

(35) Bailis, R.; Smith, K. R.; Edwards, R. Kitchen Performance Test (KPT); Household Energy Health Programme, Shell Foundation, London, UK, 2007.

(36) Fullerton, D. G.; Suseno, A.; Semple, S.; Kalambo, F.; Malamba, R.; White, S.; Jack, S.; Calverley, P. M.; Gordon, S. B. Wood Smoke Exposure, Poverty and Impaired Lung Function in Malawian Adults. Int. J. Tuberc. Lung Dis. 2011, 15 (3), 391-398.

(37) Piddock, K. C.; Gordon, S. B.; Ngwira, A.; Msukwa, M.; Nadeau, G.; Davis, K. J.; Nyirenda, M. J.; Mortimer, K. A Cross-Sectional Study of Household Biomass Fuel Use among a Periurban Population in Malawi. Ann. Am. Thorac. Soc. 2014, 11 (6), 915-924.

(38) Human Development Reports. http://hdr.undp.org/en/2015report (accessed Aug 29, 2016).

(39) Jary, H. R.; Kachidiku, J.; Banda, H.; Kapanga, M.; Doyle, J. V.; Banda, E.; Fox, C.; Gordon, S. B.; Mortimer, K. Feasibility of Conducting a Randomised Controlled Trial of a Cookstove Intervention in Rural Malawi. Int. J. Tuberc. Lung Dis. 2014, 18 (2), $240-247$.

(40) Timko, J. A.; Kozak, R. A. The Influence of an Improved Firewood Cookstove, Chitetzo Mbaula, on Tree Species Preference in Malawi. Energy Sustainable Dev. 2016, 33, 53-60.

(41) Fisher, M.; Shively, G. Can Income Programs Reduce Tropical Forest Pressure? Income Shocks and Forest Use in Malawi. World Dev. 2005, 33 (7), 1115-1128.

(42) Mortimer, K.; Ndamala, C. B.; Naunje, A. W.; Malava, J.; Katundu, C.; Weston, W.; Havens, D.; Pope, D.; Bruce, N. G.; Nyirenda, M.; et al. A Cleaner Burning Biomass-Fuelled Cookstove Intervention to Prevent Pneumonia in Children under 5 Years Old in Rural Malawi (the Cooking and Pneumonia Study): A Cluster Randomised Controlled Trial. Lancet 2016, DOI: 10.1016/S01406736(16)32507-7.

(43) Malawi Biomass Energy Conservation Project I The Gold Standard http://www.goldstandard.org/projects/malawi-biomassenergy-conservation-project (accessed Aug 29, 2016).

(44) Bailis, R. Controlled Cooking Test (CCT), Version 2.0; Berkeley Calif. Univ.: Berkeley, California, 2007. 
(45) Subramanian, R.; Khlystov, A. Y.; Cabada, J. C.; Robinson, A. L. Positive and Negative Artifacts in Particulate Organic Carbon Measurements with Denuded and Undenuded Sampler Configurations. Aerosol Sci. Technol. 2004, 38 (S1), 27-48.

(46) Park, S. S.; Hansen, A. D. A.; Cho, S. Y. Measurement of Real Time Black Carbon for Investigating Spot Loading Effects of Aethalometer Data. Atmos. Environ. 2010, 44 (11), 1449-1455.

(47) Roden, C. A.; Bond, T. C.; Conway, S.; Pinel, A. B. O. Emission Factors and Real-Time Optical Properties of Particles Emitted from Traditional Wood Burning Cookstoves. Environ. Sci. Technol. 2006, 40 (21), 6750-6757.

(48) Smith, K. R.; Uma, R.; Kishore, V. V. N.; Zhang, J.; Joshi, V.; Khalil, M. A. K. Greenhouse Implications of Household Stoves: An Analysis for India. Annu. Rev. Energy Environ. 2000, 25 (1), 741-763.

(49) Zhang, J.; Smith, K. R.; Uma, R.; Ma, Y.; Kishore, V. V. N.; Lata, K.; Khalil, M. A. K.; Rasmussen, R. A.; Thorneloe, S. T. Carbon Monoxide from Cookstoves in Developing Countries: 1. Emission Factors. Chemosphere: Global Change Sci. 1999, 1 (1-3), 353-366.

(50) Jetter, J.; Zhao, Y.; Smith, K. R; Khan, B.; Yelverton, T.; DeCarlo, P.; Hays, M. D. Pollutant Emissions and Energy Efficiency under Controlled Conditions for Household Biomass Cookstoves and Implications for Metrics Useful in Setting International Test Standards. Environ. Sci. Technol. 2012, 46 (19), 10827-10834.

(51) Jagger, P.; Hamrick, L.; Phwandaphwanda, T.; Pedit, J. Relative Fuel Efficiency, CO and PM2.5 Emissions from Three Wood-Burning Cook Stoves in Malawi. http://www.dukeenergyhealth.org/wpcontent/uploads/2011/05/Jagger-and-Pedit-Talk-May-2014.pdf (accessed Dec 23, 2016).

(52) Reid, J. S.; Eck, T. F.; Christopher, S. A.; Koppmann, R; Dubovik, O.; Eleuterio, D. P.; Holben, B. N.; Reid, E. A.; Zhang, J. A Review of Biomass Burning Emissions Part III: Intensive Optical Properties of Biomass Burning Particles. Atmos. Chem. Phys. 2005, 5, 827-849.

(53) Cheng, Y.-H. Real-Time Performance of the microAeth ${ }^{\circledR}$ AE51 and the Effects of Aerosol Loading on Its Measurement Results at a Traffic Site. Aerosol Air Qual. Res. 2013, 13, 1853-1863.

(54) McMeeking, G. R; Kreidenweis, S. M.; Baker, S.; Carrico, C. M.; Chow, J. C.; Collett, J. L.; Hao, W. M.; Holden, A. S.; Kirchstetter, T. W.; Malm, W. C.; et al. Emissions of Trace Gases and Aerosols during the Open Combustion of Biomass in the Laboratory. J. Geophys. Res. 2009, 114 (D19), D19210.

(55) Pokhrel, R. P.; Wagner, N. L.; Langridge, J. M.; Lack, D. A.; Jayarathne, T.; Stone, E. A.; Stockwell, C. E.; Yokelson, R. J.; Murphy, S. M. Parameterization of Single-Scattering Albedo (SSA) and Absorption Ångström Exponent (AAE) with EC/OC for Aerosol Emissions from Biomass Burning. Atmos. Chem. Phys. 2016, 16 (15), 9549-9561.

(56) Chen, Y.; Roden, C. A.; Bond, T. C. Characterizing Biofuel Combustion with Patterns of Real-Time Emission Data (PaRTED). Environ. Sci. Technol. 2012, 46 (11), 6110-6117.

(57) CDM: Default values of fraction of non-renewable biomass. https://cdm.unfccc.int/DNA/fNRB/index.html (accessed Aug 29, 2016).

(58) Bailis, R.; Drigo, R; Ghilardi, A.; Masera, O. The Carbon Footprint of Traditional Woodfuels. Nat. Clim. Change 2015, 5 (3), 266-272.

(59) I.P.CC. Climate Change 2013: The Physical Science Basis: Working Group I Contribution to the Fifth Assessment Report of the Intergovernmental Panel on Climate Change; Cambridge University Press: 2014.

(60) US EPA. Life-Cycle Assessment of Cookstove Fuels in India and China; EPA/600/R-15/325; US Environmental Protection Agency: Washington, DC, 2016.

(61) Zhang, J.; Smith, K. R.; Ma, Y.; Ye, S.; Jiang, F.; Qi, W.; Liu, P.; Khalil, M. A. K.; Rasmussen, R. A.; Thorneloe, S. A. Greenhouse Gases and Other Airborne Pollutants from Household Stoves in China: A Database for Emission Factors. Atmos. Environ. 2000, 34 (26), 45374549.
(62) Johnson, M. A.; Chiang, R. A. Quantitative Guidance for Stove Usage and Performance to Achieve Health and Environmental Targets. Environ. Health Perspect. Online 2015, 123 (8), 820.

(63) Masera, O. R.; Saatkamp, B. D.; Kammen, D. M. From Linear Fuel Switching to Multiple Cooking Strategies: A Critique and Alternative to the Energy Ladder Model. World Dev. 2000, 28 (12), 2083-2103.

(64) Burnett, R. T.; Pope, C. A., III; Ezzati, M.; Olives, C.; Lim, S. S.; Mehta, S.; Shin, H. H.; Singh, G.; Hubbell, B.; Brauer, M.; et al. An Integrated Risk Function for Estimating the Global Burden of Disease Attributable to Ambient Fine Particulate Matter Exposure. Environ. Health Perspect. 2014, 122 (4), 397-403.

(65) Smith, K. R.; McCracken, J. P.; Weber, M. W.; Hubbard, A.; Jenny, A.; Thompson, L. M.; Balmes, J.; Diaz, A.; Arana, B.; Bruce, N. Effect of Reduction in Household Air Pollution on Childhood Pneumonia in Guatemala (RESPIRE): A Randomised Controlled Trial. Lancet 2011, 378 (9804), 1717-1726.

(66) Romieu, I.; Riojas-Rodríguez, H.; Marrón-Mares, A. T.; Schilmann, A.; Perez-Padilla, R.; Masera, O. Improved Biomass Stove Intervention in Rural Mexico. Am. J. Respir. Crit. Care Med. 2009, 180 (7), 649-656.

(67) Jack, D. W.; Asante, K. P.; Wylie, B. J.; Chillrud, S. N.; Whyatt, R. M.; Ae-Ngibise, K. A.; Quinn, A. K.; Yawson, A. K.; Boamah, E. A.; Agyei, O.; et al. Ghana Randomized Air Pollution and Health Study (GRAPHS): Study Protocol for a Randomized Controlled Trial. Trials 2015, 16 (1), 420.

(68) World Health Organization. Indoor air quality guidelines: household fuel combustion. http://apps.who.int/iris/bitstream/ 10665/141496/1/9789241548885 eng.pdf (accessed Jun 6, 2016).

(69) Smith, K. R.; Dutta, K. Cooking with Gas. Energy Sustainable Dev. 2011, 15 (2), 115-116.

(70) Repoff, R. Bringing the Kitchen to the Lab: Data Analysis and Method Development for Lab Simulation of In-Field Operation of Biomass Cookstoves. M.S. Thesis, North Carolina State University: Raleigh, NC, 2015.

(71) Johnson, M.; Edwards, R.; Berrueta, V.; Masera, O. New Approaches to Performance Testing of Improved Cookstoves. Environ. Sci. Technol. 2010, 44 (1), 368-374. 